\title{
Evaluating product exchange options in integrated steel mills
}

\author{
Luiz de Magalhães Ozorio ${ }^{\dagger}$ \\ $I B M E C-R J$ \\ Carlos de Lamare Bastian-Pinto ${ }^{\Omega}$ \\ IBMEC-RJ \\ Tara Keshar Nanda Baidya ${ }^{¥}$ \\ UNIGRANRIO \\ Luiz Eduardo Teixeira Brandão \\ $P U C-R J$
}

\begin{abstract}
There are two basic ways to produce steel on a large scale: using iron ore and coal in blast furnaces or employing ferrous scrap in electric arc furnaces. The first requires a larger initial investment but is more competitive in terms of scale gains. The disadvantage is the need for uninterrupted operation, reducing the flexibility to adjust production. To mitigate this problem, it is common to invest in steel rolling assets, generating the possibility of diversifying production and valuable product exchange options. In this work, employing Monte Carlo simulation, we calculate the value of a product exchange option in a steel mill composed of a blast furnace with a hot roller. The results show that this option can generate a significant increase on the NPV of blast furnace steel making projects, and also reveals the importance of choosing the type of stochastic process for the steel in determining the option's value.
\end{abstract}

Keywords: Integrated steel mills; capital budgeting; Monte Carlo simulation; product exchange options; stochastic processes.

*Corresponding Author:

${ }^{*} \mathrm{PhD}$ in finance from PUCRio.

Affiliation: Assistant professor at IBMEC.

Address: Av. Presidente

Wilson, 118, sala 1114, Rio de

Janeiro - RJ - Brazil.

E-mail: Imozorio@ibmercj.br

Telephone: (21) 4503-4048

\author{
$\Omega \mathrm{PhD}$ in finance from PUC-Rio. \\ Affiliation: Assistant professor at \\ IBMEC \\ Address: Av. Presidente Wilson, \\ 118, sala 1116, Rio de Janeiro - \\ RJ - Brazil. \\ E-mail: carlos.bastian@ibmec.br \\ Telephone: (21) 4503-4146
}

${ }^{*} \mathrm{PhD}$ from the School of Business Administration of UC Berkeley.

Affiliation: Assistant professor at UNIGRANRIO.

Address: Rua Professor

José de Sousa Herdy, 1160, Duque de Caxias - RJ Brazil.

E-mail:

tarabaidya@yahoo.com.br Telephone: (21) 2247-4361
${ }^{\sharp} \mathrm{PhD}$ in finance from PUCRio. Affiliation: Assistant professor at PUC-RJ. Address: Rua Marquês de São Vicente, 225, Gávea, Rio de Janeiro - RJ - Brazil. E-mail: brandao@iag.pucrio.br Telephone: (21) 2138-9304 


\section{INTRODUCTION}

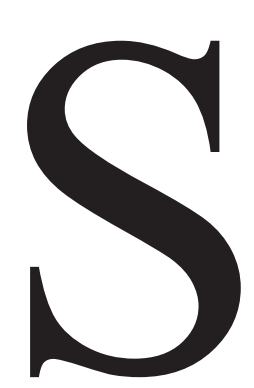

teel is made up by an alloy of iron and carbon. There are two basic ways of

producing it in large scale: the use of raw materials like iron ore and coal, by means of the method known as production in blast furnaces or integrated steel mills; or the use of scrap iron by means of electric steel plants, known as minimills or semi-integrated steel mills.

In the blast furnace production model, coal has the function of both fuel and reducer in the steel manufacturing process. As a fuel, coal allows high temperatures of approximately 1500 degrees Celsius, which are essential for the fusion of the iron ore. Coal also aids in the removal of oxygen from the iron, acting as a reducer, precisely because it allows its association with carbon. Several stages must be carried out until one achieves raw steel in the format of plates or billets. Production in a blast furnace demands - almost always - greater initial investments, but, on the other hand, it is more competitive cost- wise. Another advantage is that, once the structure for the functioning of a blast furnace is defined, the increase in productive capacity through the installation of new furnaces usually occurs at costs proportionally lower to the increase in production. This situation obviously allows for increasing gains in scale. The disadvantage is the need of an almost uninterrupted functioning of the blast furnaces, which decreases the flexibility in the adjustment of the scale of production.

Steel is a commodity with great price volatility. So that one can understand this variation, the price of a ton of hot rolled steel in the American market fluctuated during one interval from, approximately, US\$ 250.00 to, approximately, US\$1.200,00, during the period between January 2000 and September 2009. Not only that, the demand for steel is highly unstable. For this reason, it is possible to classify the steel sector as cyclical, with abrupt variations in the quantities sold between the economic "booms" and the recessions. This variability - in prices as in the quantities demanded - significantly affects revenues and, consequently, the economic results of the steel mills.

One widely used strategy in integrated steel mills, with the objective of decreasing the variability in demand and in the steel prices, is the switch of product. There are several different types of steel demanded by different sectors of the economy, and the variations in the prices of these products, although correlated, are not identical along time. To make the most of this flexibility, steel companies typically make investments in rolling assets - the final step of the steel working process, in which the format of the steel is defined, depending 
on the intended use - generating the possibility of diversification of production and valuable options of product switch.

The objective of this article is to evaluate the incremental benefit of the options of product switch in the steel industry, more specifically in integrated mills. To this end, a hypothetical case will be used to determine the value of a productive process involving the investment in a blast furnace and a hot rolling mill, simulating, through the Monte Carlo Simulation, that project's value based on these two types of different stochastic processes: Geometric Brownian Motion (GBM) and Regression to the Mean Reversion Movement (MRM).

To facilitate the understanding of the work, it was structured in the following manner: after this (i) introduction, (ii) there will be a review about the real options in project evaluation and, then, (iii) an overview of the steel sector will be presented. Finally, (iv) there will be a case study and (v) general conclusions.

\section{PROJECT ANALYSIS BY THE REAL OPTIONS THEORY}

The traditional view of finances on corporate investment is that companies should only invest in projects when the expectation of a return is greater than the minimum hurdle rate of return (opportunity cost of capital). The internal rate of return $(I R R)$ and the net present value (NPV) currently constitute the most widely used criteria in the analysis of investment opportunities. These techniques use expected cash flows from projects and risk adjusted rates. Among them, the $N P V$ is considered the most robust tool for demonstrating the creation of value for investors, and allowing the prioritization of projects in decisions that involve the choice between multiple investment opportunities.

In situations where there is high uncertainty and significant managerial flexibility, however, it is possible to realize that the traditional evaluation rules are not capable of providing complete answers for the investment decision. It is precisely in this context that it is necessary to seek another type of tool that considers the optimization process of the managerial choices in environments of uncertainty. These tools are the evaluation method of real options.

The real options approach considers the present value of future cash flows generated by real assets (projects), contingent on the exercise of optimizations determined by means of the use of strategic alternatives in the most ample states of nature possible during the life of the real asset. The objective of these optimizations - the use of strategic options - is the 
maximization of the value to the stockholder, contingent on the state of nature being revealed in the future

During the last decades, the evolution of financial models, along with the progress in computer techniques, has increased considerably the use of the real options theory in a wide range of industries with different types of approaches in Brazil and the world. Myers (1977) was the first to use the term real options based on the idea that real assets could be evaluated in an analogous manner to financial options. Tourinho (1979) used the theory in studies applied to natural resource exploration projects. Later, Brennan \& Schwartz (1985) developed applications of options of temporary interruption of the operations and abandonment of mining projects. Another relevant contribution was made by Bjerksund \& Erken (1990), in which they evaluated temporary interruption options, of abandonment and delay and also the effect of their interactions in the development analysis of an oil field. Along the same lines, Dias \& Rocha (1999) developed an investment model under conditions of uncertainty in the exploration and production of oil.

The real options theory also began to be widely applied in the electrical sector. Herbelot (1992) studied strategic options in thermoelectric plants in the USA, with the objective of satisfying the environmental requirements of the Clean Air Act Amendment. Gomes (2002) generated a model of real options to choose the best moment to invest in thermoelectricity in

Brazil. Moreira, Rocha and David (2004) evaluated the effects of the renovation of the electric energy sector in the investments in thermoelectricity, based on the real options theory.

The scope of the real options theory also extends into the real estate market. Titman (1985) analyzed the value of delaying real estate investments in urban land in the city of Los Angeles. Quigg (1993) evaluated the prices of land in Seattle (USA) and developed a model on the option to wait to invest. Williams (1991) suggested an abandonment option as an alternative to the development of real estate. Cauley \& Pavlov (2002) modeled a waiting option to sell real estate in the housing market of Los Angeles. Fortunato, Brandão, Rosenbaum \& Rebelo (2008) calculated the value of the option of abandonment in the purchase of real estate in Brazil.

For certain sectors, an important and valuable real option might be the change in technology, which consists in the possibility of altering the varied offer of products or the use of inputs in the productive process. It means, specifically, that if the demand or price of products that the company produces or consumes is changed, the management has the 
alternative of altering the choice of final products. In a similar manner, in cases in which the final products can be produced with the use of different inputs, the management can choose the set of inputs that proves to be the most profitable and pertinent to the scenario that would reveal itself in the future. Among important works developed on product switch options, we can quote those by Bastian-Pinto, Brandão \& Hahn (2009). These authors analyzed the product switch option in the Brazilian ethanol industry, more specifically the substitution of the final product between sugar and alcohol, taking also its prices as correlated regression to the mean processes. More recently, Dockendorf \& Paxson (2009) analyzed the option of product switch in a fertilizer industry, more specifically the trade of the production output: ammonia and urea. This important managerial flexibility - the changing of the final product exists in the steel industry and constitutes an important strategy to lessen the great volatility in steel demand and prices. Presently, depending on the intended use, several types of steel can be produced, varying in terms of format, different levels of purity, or also through the intentional adding of chemical elements for the obtainment of desirable characteristics like resistance to corrosion or greater levels of hardness. Among the several uses of steel products, the following can be highlighted: civil construction, automobile and capital goods production, home appliances, packaging and tubes for several uses. This option requires, however, investments in the production plants, more specifically in the rolling units, for the manufacturing of various steel products. No works were found in the literature relating to the valuation of the flexibility of product switch in the steel mill.

It is important to note that the uncertainties present in projects are frequently modeled as a Geometric Brownian Motion (GBM), which assumes a constant growth (drift) rate and a variance that grows linearly in time. Its mathematical formulation can be given by the differential equation: $d S=\mu S d t+\sigma S d z$, where $\mu$ is the drift of the process and $\sigma$ it's the volatility parameter. Nonetheless, there may be cases where the uncertainty does not follow a GBM. This is the case when the uncertainty depends on an equilibrium level such as the case of non-financial commodities (Pindyck, 2001, 1999, Brennan \& Schwartz, 1985). Specifically in relation to the price of commodities or commodity producing assets, it is a common assumption that these follow a Mean Reverting process - MRM model (Schwartz, 1997, Schwartz \& Smith, 2000). In this case, the expected value of the process will revert to a level of balance in the long run, and contrary to the GBM, its variance will be restricted to a limit.

The mathematical formulation of the geometric reversion process know as model 1 by Schwartz (1997) is given by the differential equation: $d S=\eta(\ln (\bar{S})-\ln (S)) S d t+\sigma S d z$, in 
which $\eta$ is the velocity of the process regression, $\bar{S}$ the level of long term balance and $\sigma$ is the volatility parameter. However, there is no consensus about which stochastic process is more adequate, and as Dixit \& Pindyck (1994) suggest, the definition of the process depends as much on statistical as much as theoretical considerations.

\section{OVERVIEW OF THE STEEL SECTOR}

Steel is an alloy of iron and carbon that is distinguished from molten iron, basically, for having a lower carbon content and greater malleability (deformation capacity), as a result of the differences in the productive processes used in the manufacturing of the two products.

The beginnings of steel production pre-date the Christian era. There are records that the Egyptians, in 900 B.C., already had knowledge of the techniques for producing steel that were used in the manufacturing of weapons like knifes and swords. However, the wide scale production of steel started only in the 19th century, after the Industrial Revolution, when the technological evolution made possible the construction of larger and more efficient furnaces.

Presently, depending on the intended use, several types of steel can be produced, varying in terms of format, different levels of purity, or also through the intentional adding of chemical elements for the obtainment of desirable characteristics like resistance to corrosion or greater levels of hardness. Such characteristics, added to the abundance of existing raw materials for its production and its relative low cost, confer strong advantages to steel if compared to the competing materials, making this the most important metallic alloy in modern society.

According to research carried out by IBS, currently the consumption of steel accounts for $90 \%$ of all metallic alloys used around the world. Among the several uses of steel products, the uses should be highlighted: in civil construction, in automobile and capital goods production, in home appliances, packaging and tubes for several uses. It is estimated that, in Brazil, these segments demand, approximately, 95\% of all the steel consumed.

The investments in the steel sector are, however, fraught with uncertainties. The main risk factor in the sector is its cyclical characteristic, which causes great variations in prices and quantities demanded by the market. So that one can understand this variability, the price of a ton of hot rolled steel in the American market fluctuated during one interval from, approximately, US\$ 250.00 to, approximately, US\$1,200.00, during the period between January 2000 and September 2009. Such variability is potentialized by the leveraged 
operational structure in the sector, with a strong participation of fixed costs, causing great volatility in the returns in steel projects, as well as in the stock of companies in this segment.

\subsection{Productive processes}

There are basically two forms of large scale steel production: using as raw materials iron ore and coal in blast furnace mills; or in mini-mills (electric steel plants), using molten scrap iron in electric furnaces. The blast furnace mills are also known as integrated mills, whereas the electric ones are called semi-integrated mills.

In the blast furnaces, coal performs the functions of fuel and reducer in the manufacturing of steel, allowing high temperatures to be reached (above 1000 degrees Celsius), which is essential for the fusion of the ore and helping to remove the oxygen from the iron, allowing its fusion with carbon. In this process, the iron is liquefied, becoming pig iron. After treatments to remove impurities, we arrive at the raw steel, in the shape of plates or billets, which later are transformed into sheets, bars, strips, wires, and in other products, with varied uses. The production process in the blast furnace mills can be summarized in five basic steps: preparation, reduction, refining, casting and rolling.

The great difference in the steel productive processes in the blast and electric furnaces is that, in the second method, there is no reduction phase. For this reason, the mini-mills are also known as semi-integrated mills. The scrap iron is placed directly in the electric furnaces during the refining stage for the production of raw steel that is later rolled and transformed according to the desired use. In the place of scrap, these mills can also use pig iron as a raw

material, produced many times in furnaces that operate with charcoal by the so-called "pig iron producers".

Figure 1 presents a Simplified Production Flow demonstrating the steps described for 2 production models: blast furnace mills (integrated mills) and mini-mills (semi-integrated mills). 


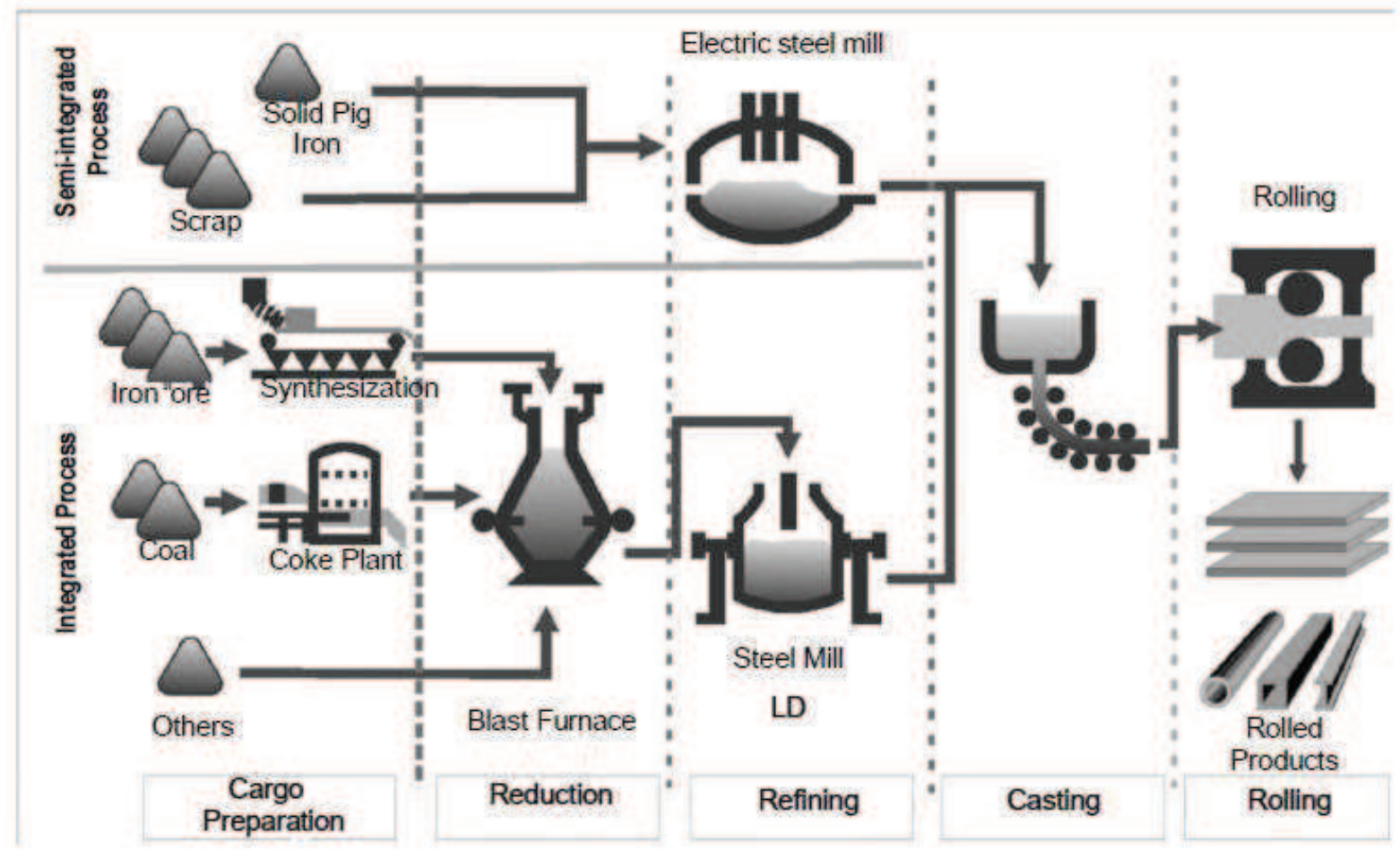

Figure 1 - Stages of the Productive Processes of Steel - Simplified Production Flow.

Source: IBS.

\subsection{Steel Products}

The technological evolution that occurred in the steel industry, during the last decades, allows a large versatility in the use of steel nowadays. The current types of steel products are innumerable and vary in terms of composition of the alloys, formats and types of finish.

The sophistication achieved is such that, depending on the level and type of demand, specific and customized products can be developed for clients' needs. For the automotive industry, for example, special steels are produced with high resistance to corrosion, with several different thicknesses adequate to the production of parts and body and with coatings and finishes intentionally prepared for the generation of efficiency in the production of vehicles.

Besides the advantages to the transformation industry, high technology in the steel and iron industry has been generating benefits for end consumers, by providing greater durability and safety to products made of steel. For example, one can quote the high power and ductility of the steel used currently in the production of vehicle chassis. With this type of special material, it is possible to develop in the body of automobiles "intelligent crumple zones" which, in the case of collisions, initially deform more easily to better absorb the impact, later becoming more rigid by means of a transformation in its structure, which provides better protection to the driver and other passengers in the vehicles. 
Specifically in relation to the composition of the steel alloys, these can vary in terms of purity or by the addition of substances for the obtainment of desirable attributes. The classification of common steel is given to alloys with content lower than $2 \%$ of added elements to the iron and carbon. Steels with $2 \%$ and $5 \%$ of other elements in their composition will be conferred the label of low-alloy, and for those above 5\%, high-alloy steel.

Among the unwanted substances that typically are present in the composition of steel, there are sulphur and phosphorus. These elements intervene, negatively, in the physical properties of steel, causing it to have lower resistance and malleability. The addition of magnesium during the refining process, a product that is anti-sulphurating, seeks, among other procedures, to correct this problem, making steel less brittle and more adequate for the machining stage.

Nickel and chrome are examples of substances that are added to steel to obtain desirable properties. With participations in the composition of steel many times higher than $20 \%$, these elements together with iron and carbon create a high-alloy that is known as stainless steel. This alloy was discovered in England, during the early 20th century, by Harry Brearley, while he researched more resistant metallic alloys for the weapons industry. Among the main characteristics of stainless steel are: its high resistance to corrosion, high temperatures and abrupt variations in temperature; ease of cleaning as a result of its low surface rugosity, conferring it a hygienic appearance; adequate mechanical resistance added to the facility of conformation and also of union with other materials. These qualities are appreciated in the production of several products like: domestic cutlery and utensils, vehicle tailpipes, visual signage plaques, among others.

Additionally to the development of special alloys like stainless steel, another technology has been creating significant improvements in steel products, regarding resistance and corrosion, which is the employment of coatings such as zinc. An evolution in the area of coated steels is a process known as electro-plating, by which means steel is covered in a protective layer of zinc and still suffers a series of thermal treatments that give it greater protection against atmospheric oxidation. The galvanized steel plates present also a good welding quality and better adaptation to painting when compared to plates with pure zinc coating.

As to the format and levels of finishing, there are several possibilities that differ in their adaptation to their intended use. Among the refining and rolling stages, there is the casting phase, in which raw steel (or semi-finished) is produced, which can be manufactured in the 
shape of plates, blocks or billets. Through the rolling process, the semi-finished steel is reheated again and mechanically pressed, generating flat steels and long steels.

The flat steels are characterized by having a width much greater than its thickness, differentiating it mainly in terms of the thickness of the plates and coils produced. In daily life, there is a great variety of products using flat iron, which can go from the material used in the production of beverage cans to thick plates used in the construction of ships.

The long steels are characterized by having a length that is extremely superior to that of the other dimensions. There are examples of long steel profiles, bars, tubes, bars and machine wire. The use of long steels is diverse, and they can be employed directly in civil construction, or also as a raw material in the production of automobile parts, manufacturing of nails, screws, among others.

\section{CASE STUDY: PRODUCT SWITCH OPTION IN INTEGRATED STEEL MILLS}

One important strategic alternative found in the steel mill is the choice of the Technology Change Option, more specifically the Product Change Option. In situations in which the demand or price of the steel products that the company produces changes, the management has the alternative of altering the output of production to mix that can prove to be more profitable. The calculation of the value of this option starts with the simulation of the project cash flow in every possible state of nature and in each period, considering the possibilities of a mix of products and also possible adjustment costs in production.

In this section, using the Monte Carlo Simulation, a Product Switch Option in Integrated Steel Mills will be prices. Initially, a base case will be presented that consists of the valuation of a blast furnace project and a hot rolling mill, both with a production capacity of 2.8 million tons/year of steel, using the discounted cash flow method, with the purpose of determining the static NPV of this project. After that, the above real option will be calculated, using two different types of stochastic processes: GBM and MRM, for the modeling of the prices of the output products. At the end of the section, a comparative analysis will be made of the obtained results, with the purpose of recognizing the potential of the earned value and the possible implications of the adoption of each type of price process tested in the decision making in investment projects in the steel industry.

\subsection{Base Case}

We consider an integrated steel mill project composed of a blast furnace with an annual production capacity of 2.8 million tons of steel, whose investments for the assembly of the 
plant total an amount of $\mathrm{R} \$ 4,140$ million. The capital cost for this type of project is $10.12 \%$ a year, in real terms. This is estimated considering the risk free interest rate $(r)$ of $5 \%$ in actual terms, the mean beta in the sector of 0.93, obtained from Damodaran (2011), and the market risk premium is estimated based on the difference between the historical average of Ibovespa returns, obtained from BM\&FBOVESPA (2011), in actual terms of 10.5\% (E(rm)) - referring to the period between 1994 to 2010 - and the fixed income return $(r)$ in Brazil in actual terms. Based on the CAPM formula, we arrive at the estimated value:

$$
K=r+\operatorname{Beta} \times(\mathrm{E}(r m)-r)=5 \%+0.93 \times(10.5 \%-5 \%)=10.12 \%
$$

At the time of the valuation of the project, the net revenue per ton of steel plate was US\$ 500, with the dollar traded at R \$ 1.80. The analysis of the historic series of deflated prices for six different types of steel in Brazil obtained from the IBS (2009) for the period between January /2000 and April/2009 (Figure 2), shows an average growth rate of 4.67\% a year, in actual terms. However, it is considered more appropriate to use a drift of $2.5 \%$ in actual terms for the prices of steel products, since structural changes have occurred in the sector after the end of the economic crisis, at the end of 2008 and in 2009. This value of drift used (2.5\%) was obtained from a series of steel plates obtained at Bloomberg (2009), covering January/1996 to December/2009, with a growth rate (drift) during this period of $2.48 \%$ on average, per year. This series was not used for the other parameters, because contemporary series are necessary for the two types of steel (plates and hot coils), in order to determine the specific volatilities and speed of regression to the mean, and the correlation between the returns of the two prices. In all the analysis below, the net revenue $S$ per ton per type of steel will be modeled, considered as the price of this type of steel (in US\$/ton). 


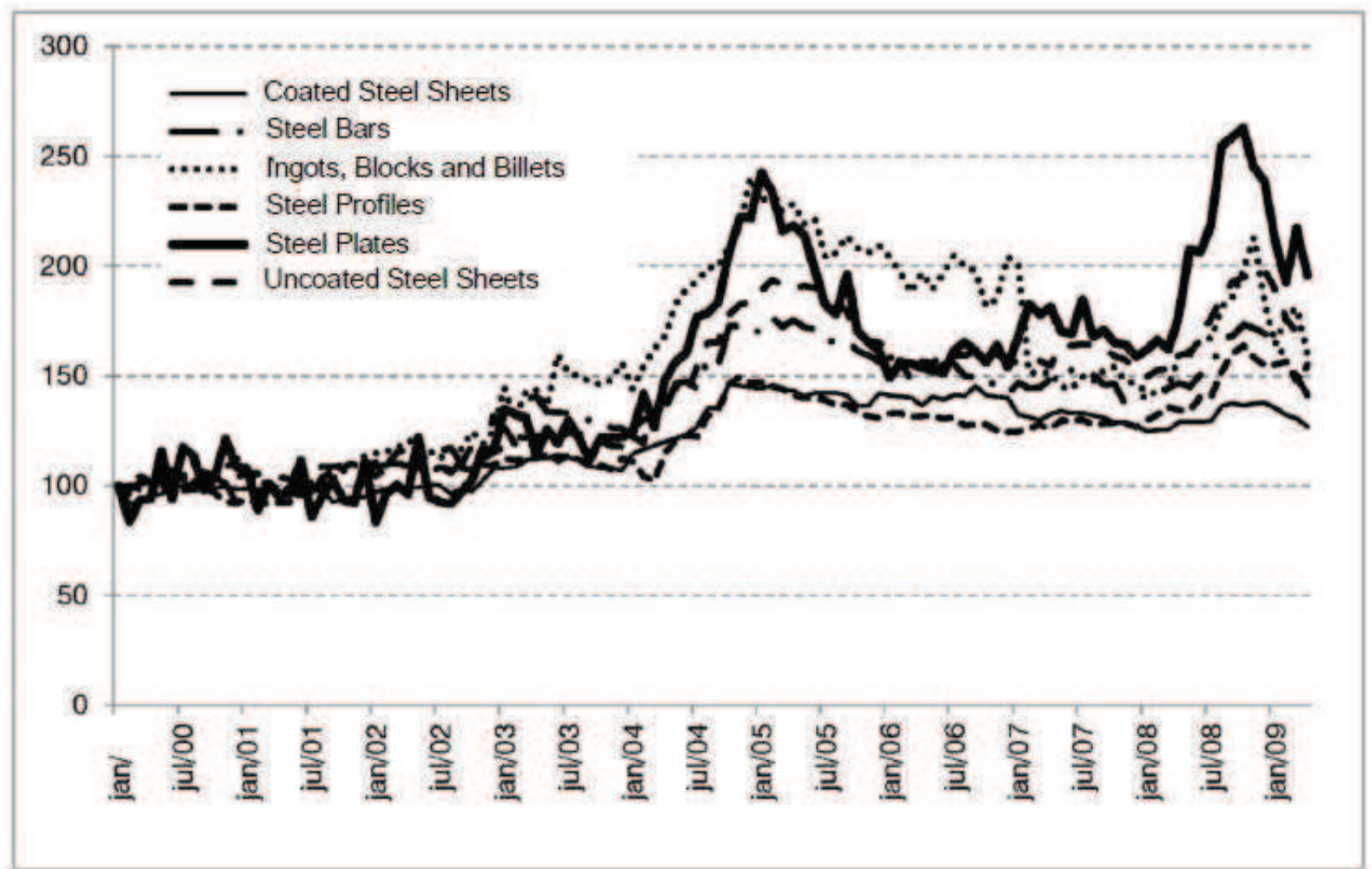

Figure 2- Index of Deflated Monthly Prices of Steel Products in the Brazilian Market - Jan/2000 to Apr/2009 Source: IBS, prepared by the authors.

Among the main production costs is iron ore, whose price on the date of the work is US\$ 45 per ton. It is supposed that the quarterly price increases of the ore are equivalent to the estimated drift for the steel prices. The other production costs, except for depreciation (coal, coke, energy, other materials, personnel and maintenance), total US\$ 255 per ton of produced steel and the general expenses (administrative and commercial) reach R\$ 200 million in annual terms. It is supposed that these other production costs and expenditures will be corrected in time only by inflation $(0 \%$ in actual terms) and even though the blast furnace operates, on average, at $90 \%$ of its installed capacity. Therefore, they are considered without growth in the analysis. The initial investment will be depreciated linearly during 20 years and, by simplification, it is considered that the necessary reinvestments for the maintenance of the plant are similar to the depreciation. In this manner, the cash flow in quarterly terms can be calculated by the equation (1):

$$
F C X_{s}=\left[C a p \times U C \times\left(S_{s}-M_{s}-O C P\right) \times T C-D A-D G\right](1-A I) \Delta s
$$

Where:

$F C X_{s}-$ Project Cash Flow during the quarter $s$ (in $\mathrm{R} \$ 1,000.00$ );

Cap - Plant Installed Capacity in tons/year;

$U C-$ Use of the Installed Capacity; 
$S_{s}-$ Net Revenue per Ton of Steel Plate during the quarter $s$ (in US\$);

$M_{s}-$ Cost of the Iron Ore by Ton of Steel during the quarter $s$ (in US\$);

$T C$ - Exchange Rate (R\$/US\$);

$O C P$ - Other Production Costs (in US\$)

$D A$ - Depreciation and Amortization (in R $\$ 1,000.00) /$ year

$D G-$ General Expenses (in R $\$ 1,000.00) /$ year

$A I-$ Tax Rate

$\Delta s-0.25$ (quarterly period)

Based on five years of quarterly projections of cash flows (that is: 20 quarters), after which was considered a perpetuity without growth, a value of R \$ 4,928 million was estimated for the project, which determines a static NPV of R\$ 788 million.

The plant valuated in the base case would have as the only output steel plates, which is an input for several other steel products. An investment opportunity is considered then on a rolling mill that would allow the production of hot coils, a product of greater earned value with several industrial uses, prepared from the steel plates. The disbursement of capital for the assembly of the rolling mill with a capacity for 2.8 million tons/year is $\mathrm{R} \$ 2,880$ million, depreciable during 20 years. On the evaluation date, the price of the ton of the hot coil is US\$ 750, and the American dollar is valued at R \$ 1.80. It is supposed that the prices of the hot coils, in a similar manner to that of the steel plates, will grow during the next five years at an average rate of $2.5 \%$ p.a., in actual terms. The installation of the rolling mill would imply an increment in annual general expenses of R 120 million and US\$ 100 in production costs per ton of steel produced. By simplification, it is considered that the necessary reinvestments for the maintenance of the plant are similar to the depreciation.

The incremental cash flow, in expected terms, obtained with the implantation of the rolling mill can be defined by the equation (2):

$$
F C X I_{s}=\left[C a p \times U C \times\left(\left(S_{s}^{*}-S_{s}-O C P^{*}\right) \times T C\right)-D G^{*}-D A^{*}\right](1-A I) \Delta s
$$

In which:

$F C X I_{s}-$ Incremental Cash Flow of the Coiled Hot-Rolled Strips during the quarter $s$ (in R $\$ 1,000.00$ ); 
Cap - Plant Installed Capacity in tons/year;

$U C$ - Use of the Installed Capacity;

$S_{s}^{*}-$ Net Revenue per Ton of the Coiled Hot-Rolled Strips during the quarter $s$ (in US\$);

$S_{s}-$ Net Revenue per Ton of Steel Plates during the quarter $s$ (in US\$);

$O C P^{*}$ - Incremental Production Costs of the Coiled Hot-Rolled Strips per Ton (in US\$);

$T C$ - Exchange Rate (R\$/US\$);

$D G^{*}$ - Incremental General Expenses with the Production of Coiled Hot-Rolled Strips (in R $\$ 1,000.00)$ /year;

$D A^{*}$ - Incremental Depreciation and Amortization with the Investment in the Rolling Mill (in R\$ 1,000.00)/year;

$A I$ - Tax Rate

$\Delta s-0.25$ (quarterly period)

Considering a capital cost for this type of project of $10 \%$ per year, in actual terms, the incremental static NPV of the coiled hot-rolled strips is estimated in R\$796,830 million.

\subsection{Product Change Option in Integrated Mills - GBM}

The incremental NPV static analysis of the rolling mill undervalues, however, the important product switch alternative, by assuming that during the entire evaluation period the production will be exclusively of coiled hot-rolled strips. It occurs that, during certain periods, as a result of the oscillations in the prices of steel products provoked by momentary variations in supply and demand, the production of steel plates can be an alternative more interesting than the production of coils. The value of the product switch option can then be obtained directly by a neutral simulation to the risk of incremental flows obtained by the sale of plates in relation to the sale of strips, and the due discount of these flows by the risk free tax, as demonstrated by equations (3) and (4):

$$
\begin{gathered}
O P T^{0}=\frac{\sum_{s=1}^{M} E_{0}^{*}\left[F C X I_{s s}^{*}\right]}{(1+r)} \\
F C X I_{s}^{*}=\operatorname{Max}\left[\operatorname{Cap} \times U C \times\left(S_{s}-S_{s}^{*}+O C P^{*}\right) \times T C \times(1-A I) \Delta s ; 0\right]
\end{gathered}
$$


In which:

$O P T_{0}$ - Value of the Change Option in time 0 (in $\mathrm{R} \$ 1,000.00$ );

$E_{0}^{*}[\cdot]-$ Neutral Expectation to Risk in time 0;

$F C X I_{s}^{*}$ - Incremental Cash Flow of the Sale of Steel Plates in relation to the Sale of Coiled Hot-Rolled Strips during the quarter $s$ (in R\$ 1,000.00);

Cap - Plant Installed Capacity in tons/year;

$U C$ - Use of the Installed Capacity;

$S_{s}-$ Net Revenue per Ton of Steel Plates during the quarter $s$ (in US\$);

$S_{s}^{*}-$ Net Revenue per Ton of the Coiled Hot-Rolled Strips during the quarter $s$ (in US\$);

$T C$ - Exchange Rate (R\$/US\$);

$O C P^{*}$ - Incremental Production Costs of the Coiled Hot-Rolled Strips per Ton (in US\$);

$A I-$ Tax Rate

$\Delta s-0.25$

To obtain Risk-Neutral Expectation, $E_{\alpha}^{*}[\cdot]$, a Monte Carlo Simulation method was used of the Risk-Neutral GBM of the Net Revenue processes $(S)$ of the Steel Plates and Hot Strips, using@Risk software, through the equation (5):

$$
\left.S_{s}=S_{s-1} \exp _{[}\left[\mu-\pi-\frac{1}{2} \sigma^{2}\right) \Delta s+\sigma N(0,1) \sqrt{\Delta s}\right]
$$

In which:

$S_{s}-$ Net Revenue per Ton of Steel Plates during the quarter $s$ (in US\$);

$\mu$-parameter of the process drift (per year);

$\pi$ - process risk premium;

$O$ - volatility parameter (per year);

$N(0,1)$ - normal distribution of 0 average and 1 standard deviation. 
Assuming that the steel prices follow a GBM, growth drifts were used for the log of $S_{s}$ and $S_{s}^{*} \quad$ similar to those used in the projection of cash flows of the base case, of: $\left(\mu-\sigma^{2} / 2\right)=$ $2.5 \%$. As a volatility parameter for the steel plates, $\sigma=34.32 \%$ was used, estimated on $\log$ returns of the price indices of the steel plates of the series presented in Figure 2. As a parameter of volatility for coiled hot-rolled strips, $\sigma=9.84 \%$ was used, also estimated from log-returns of the price indices of uncoated steel plates from the series presented in Figure 2. Additionally, the two price processes previously mentioned were supposed as correlated, being the parameter $\rho=0.238$ estimated from the correlation of log-returns of $S_{s}$ and $S_{s}{ }^{*}$. For the simulations of the correlated processes, the Cholesky decomposition was used, according to which two random variables, both following normal correlated distributions $\left(Z_{A}\right.$ and $\left.Z_{B}\right)$, can be simulated together by the equation: $Z_{B}=\rho Z_{A}+\left(1-\rho^{2}\right)^{0,5} Z_{w}$, in which $Z_{W}$ is $Z_{A}$ are independent pattern normal distributions. For the modeling of the option, it was also necessary to estimate the risk premiums $\left(\pi_{S}\right.$ and $\left.\pi_{S^{*}}\right)$, which, subtracted from the drifts $(\mu-$ $\sigma^{2} / 2$ ), allow the discount of the expanded cash flows using risk free interest rates, $r=5 \%$, in the case in question. The estimation of the risk premium can be made by the method described by Hull (2006, chap. 31) and used in the works of Irwin (2003), Brandão and Saraiva (2007), Blank, Baidya and Dias (2009). The method estimates the premium from the correlation of the returns of the asset and the market returns, of the volatility of the asset returns, of the volatility of the market returns and the market risk premium, as demonstrated in the equation (6):

$$
\pi_{i}=\frac{\rho_{i, m} \sigma}{O_{m}} \pi_{m}
$$

Where:

$\pi_{i}$ - process risk premium of asset prices $i$

$\rho_{i, m}$ - correlation of the returns of asset i with market;

$o_{i}$ - volatility of the returns of asset i;

$o_{m}$ - volatility of the market returns;

$\pi_{m}-$ market process risk premium; 
Using the methodology described above, the risk premiums were estimated in $\pi_{S}=$ $0.33 \%$ and $\pi_{S^{*}}=0.37 \%$. In possession of the estimated incremental flows, $E_{0}^{*}\left[F C X I^{*}\right]$, discounted at a risk free rate $r=5 \%$ p.a., a value of $\mathrm{R} \$ 760$ million was obtained for Product Change Option, which would increase in $95 \%$ the static NPV estimated for the coiled hotrolled strips project, as can be observed in Figure 3, referring to the Monte Carlo Simulation.

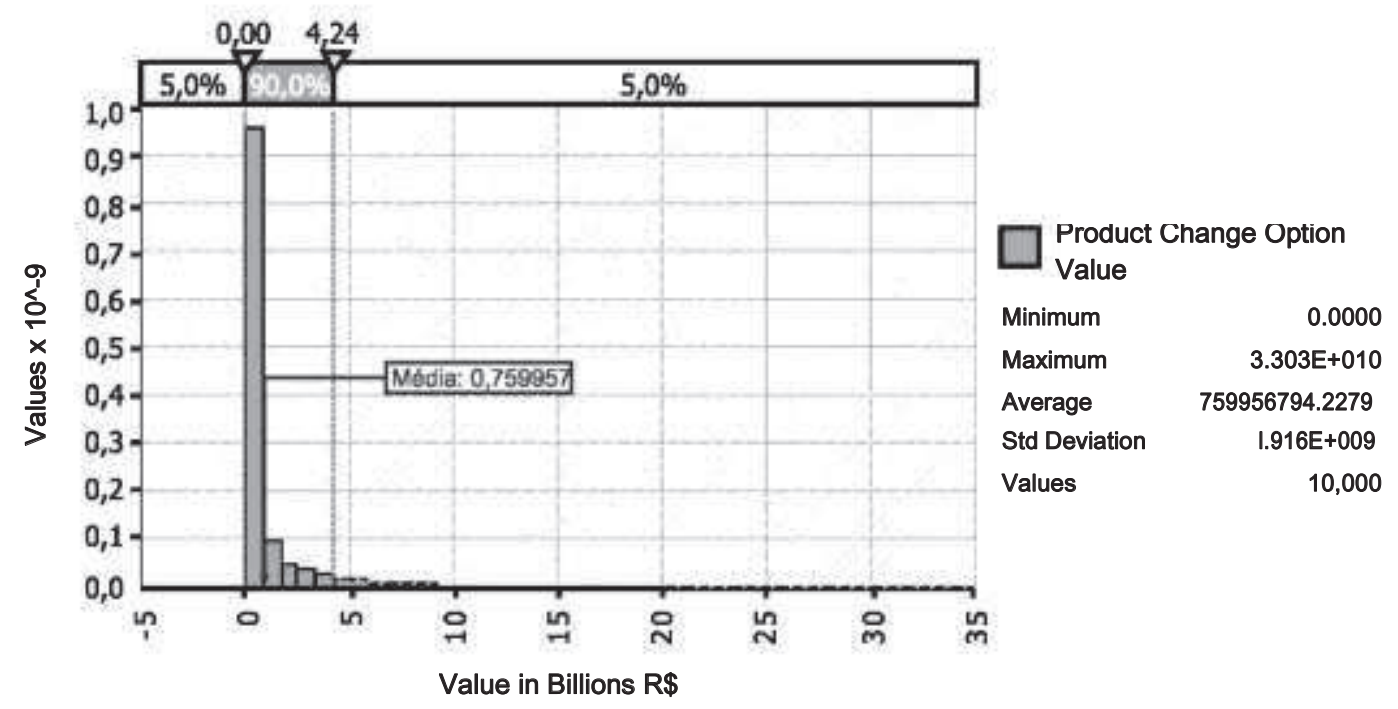

Figure 3 - Product Change Option Value (GBM) in Billions of Reais

\subsection{Technology Change Option in Integrated Mills - MRM}

Based on the same information used in the previous case (sections 4.1 and 4.2), in this section, a technology (product) switch option will be evaluated in an integrated steel mill, supposing, in this case, that the steel prices follow a regression to mean movement. The chosen stochastic process was Schwartz's Model 1 (1997), whose risk-neutral simulation form is presented in equation (7):

$$
\left.S_{s}=\exp _{\|} \ln S_{s-1} e^{-\eta \Delta s}+\left(\ln \bar{S}-\frac{\sigma^{2}}{2 \eta}-\lambda\right)\left(1-e^{-\eta \Delta s}\right)+\sqrt{\frac{1-e^{-2 \eta \Delta s}}{2 \eta}} N(0,1)\right)
$$

In which:

$S_{S}-$ Net Revenue per Ton of Steel Plates in s (in US\$);

$\ln \bar{S}-\log$ of the mean long term of the prices;

$\eta$ - parameter of the velocity of the process's regression to mean (per year);

$\lambda$ - normalized risk premium of the process;

$O$ - process volatility parameter (per year); 
Once again the annual parameters were estimated based on the series of price indices on steel plates, presented in Figure 2, being these: $\eta_{S}=0.67, \sigma_{S}=35.1 \%, \bar{S}=551.10$ US $\$ /$ ton, respectively, the regression velocity parameters, the volatility, and the long term average of the steel plates. And: $\eta_{S^{*}}=0.18, \sigma_{S^{*}}=9.94 \%, S^{*}=826.65 \mathrm{US} \$ /$ ton, the same parameters referring to the series of uncoated steel sheets, used for the calculation of the net revenue of coiled-hot-rolled strips. The approach used for the estimation of the MRM process parameters was that developed by Bastian-Pinto, Brandão and Hahn (2009).

In a manner similar to that performed in GBM, it is also necessary, in this case, to subtract the risk premium in the model to obtain the risk-neutral process of the simulation. In the case of the MRM, the risk premium $\pi$ will be normalized dividing this for the regression velocity parameter: $\lambda=\pi / \eta$. The standardized risk premiums estimated for the price processes of the plates and coiled hot-rolled strips were estimated, respectively, in: $\lambda_{S}=0.047$ and $\lambda_{S^{*}}=$ 0.112 .

Considering the alterations in the steel price processes, changes were observed in the NPV of the projects without flexibility, for the simple supposition that the steel prices follow a MRM and not a GBM, as in the original base case. With this modification in the model, there was a reduction in the static NPV of the blast furnace from R $\$ 789$ million to $\mathrm{R} \$ 556$ million, and in the case of the coiled hot-rolled strips, the static NPV, which was R 797 million on GBM, changed to R \$ 320 million, with the change to the MRM. Starting with the discount for the risk free rate of the estimated incremental flows, $E_{0}^{*}\left[F C X I^{*}\right]$, a value of $\mathrm{R} \$$ 268 million was obtained for the Product Change Option, with the supposition that steel prices follow a MRM, as may be observed in Figure 4, referring to the Monte Carlo Simulation. 
variable is the price of steel and its byproducts. As these have strong characteristics of commodities, it is reasonable to think that they can be guided by a regression to mean process and not by a GBM, as frequently is supposed in works involving real options.

Tables 2, 3 and 4 present the sensitivity of the value of the option in relation to the parameters: drifts, volatilities and correlation of two price processes (plates and coiled hotrolled strips) following the GBM.

Table 2 - Sensitivity of the Technology Change Option Value to Different Values of Drifts of the Steel Prices Processes according to GMB, in RS Million

\begin{tabular}{|l|ccc|}
\hline \multicolumn{4}{|c|}{ Sensitivity of the Technology Change Option Value } \\
\hline \multirow{3}{*}{ Drift of the Plate } & Drift of the Coiled Hot-Rolled Strips \\
1.0\% & $\mathbf{1 . 0 \%}$ & $\mathbf{2 . 5 \%}$ & $\mathbf{4 . 0 \%}$ \\
\cline { 2 - 4 } $\mathbf{2 . 5 \%}$ & 743.7 & 689.6 & 574.4 \\
$\mathbf{4 . 0 \%}$ & 855.7 & 760.0 & 706.5 \\
& 983.6 & 900.3 & 785.7 \\
\hline
\end{tabular}

Source: Prepared by the authors.

Table 3 - Sensitivity of the Technology Change Option Value to Different Volatilities of the Steel Prices Processes according to GMB, in R\$ Million

\begin{tabular}{|l|ccc|}
\hline \multicolumn{4}{|c|}{ Sensitivity of the Technology Change Option Value } \\
\hline & \multicolumn{3}{|c|}{ Vol. of Coiled Hot-Rolled Strips } \\
Vol. of Plate & $\mathbf{5 . 0 \%}$ & $\mathbf{1 0 . 0 \%}$ & $\mathbf{1 5 . 0 \%}$ \\
$\mathbf{2 5 . 0 \%}$ & 429.3 & 443.7 & 512.6 \\
$\mathbf{3 5 . 0 \%}$ & $\mathbf{7 4 2 . 3}$ & 764.1 & 833.0 \\
$\mathbf{4 5 . 0 \%}$ & 1145.0 & 1165.0 & 1202.0 \\
\hline
\end{tabular}

Source: Prepared by the authors.

Table 4 - Sensitivity of the Technology Change Option Value to Different Levels of Correlation between the Steel Prices Processes according to GMB, in RS Million

\begin{tabular}{|c|c|}
\hline \multicolumn{2}{|c|}{ Sensitivity of the Technology Change Option Value } \\
\hline $\begin{array}{c}\text { Correlation between } \\
\text { of the Processes }\end{array}$ & $\begin{array}{c}\text { Option Value } \\
\text { Technology Change }\end{array}$ \\
$\mathbf{5 \%}$ & 828.8 \\
$\mathbf{1 5 \%}$ & 792.5 \\
$\mathbf{2 5 \%}$ & 757.2 \\
35\% & 717.6 \\
$\mathbf{4 5 \%}$ & 690.3 \\
\hline
\end{tabular}

Source: Prepared by the authors.

As can be observed in Table 2, considering the hypothesis that the steel prices follow a GBM, the Technology Change Option presents larger values the larger the tendency for drift of steel plates in regards to the drift of the coiled hot-rolled strips. This analysis is important, being that a base case was assumed with a drift of $2.5 \%$ for both stochastic variables, despite the series of available indices indicating higher tax values during the analyzed period. As was already explained, this period (2000 to 2009 - Figure 2) predates structural changes in the sector, that should not allow the maintenance of the growth rates presented and, therefore, the 
growth rate of a longer series was used, that, however, does not cover all the products necessary to the present analysis. However, in analyzing the sensitivity of the option value to the drifts of products, it can be observed that the this value remains significantly high for any simulated value, being the lowest at $\mathrm{R} \$ 690$ million and the highest at R\$ 984 million, demonstrating that the option has a significant value even for low values of drift.

In Tables 3 and 4, it is possible to observe that the value of the Technology Change Option increases as the volatility of steel prices increases, while the option value decreases as the correlation between the prices increases.

Tables 5 and 6 demonstrate the sensitivity of the value of the option in relation to the parameters: regression speed and long term balance level of two price processes (plates and coiled hot-rolled strips) following the MRM.

Table 5 - Sensitivity of the Technology Change Option Value to Different Regression Velocities of the Steel Prices Processes according to MRM, in RS Million

\begin{tabular}{|c|c|c|c|}
\hline \multicolumn{4}{|c|}{ Sensitivity of the Technology Change Option Value } \\
\hline \multirow{2}{*}{$\begin{array}{l}\text { Velocity of } \\
\text { Ver. of the Plate }\end{array}$} & \multicolumn{3}{|c|}{$\begin{array}{c}\text { Velocity of Version of Coiled Hot-Rolleo } \\
\text { Strips }\end{array}$} \\
\hline & $15.0 \%$ & $20.0 \%$ & $25.0 \%$ \\
\hline $50 \%$ & 332.2 & 322.2 & 305.5 \\
\hline $70 \%$ & 259.9 & 253.1 & 245.9 \\
\hline $90 \%$ & 217.9 & 210.4 & 203.5 \\
\hline
\end{tabular}

Source: Prepared by the authors.

Table 6 - Sensitivity of the Technology Change Option Value to Different Levels of Long Term Balance of the Steel Prices Processes according to MRM, in R\$ Millions

\begin{tabular}{|l|ccc|}
\hline \multicolumn{4}{|c|}{ Sensitivity of the Technology Change Option Value } \\
\hline Level of & Level of Balance of Prices & (Laminates) \\
Balance Prices & $\mathbf{8 2 0}$ & $\mathbf{8 5 0}$ & $\mathbf{8 8 0}$ \\
\cline { 2 - 4 } (Plates) $\mathbf{5 3 0}$ & 228.4 & 216.5 & 199.8 \\
$\mathbf{5 5 0}$ & 279.4 & 265.3 & 242.4 \\
$\mathbf{5 7 0}$ & 334.7 & 307.8 & 287.6 \\
\hline
\end{tabular}

Source: Prepared by the authors.

In Table 5, considering the hypothesis that the steel prices follow a MRM, it is possible to observe that the value of the Technology Change Option reduces as the regression velocity of the processes of the steel prices increases, while, in Table 6, it is possible to observe that the value of the option is greater for higher levels of balance of the steel plate prices and for the lower levels of balance of the coiled hot-rolled strips. As to the sensitivity of the option value with regards to the variations in the other parameters of the MRM, more specifically the volatility and correlation between the processes, the conclusions are similar to those obtained for the GBM case. 
In analyzing the sensitivity of the value of the real option studied to its parameters, what draws greater attention is that the difference in value when the variables are modeled by GBM or MRM is significantly higher than any sensitivity to the process parameters. This important point indicates that the choice of stochastic process can be even more influential than the precision in the parameterization of the process when it comes to calculations of the real long duration options. In this case, the stochastic model chosen can influence the value of the option, especially by its tendency parameters (drift in GBM and level of balance in MRM), besides its variance characteristics. In this manner the choice of stochastic diffusion model is decisive for the correct evaluation of the real long duration options, especially in sectors connected to the prices of commodities.

\section{CONCLUSIONS}

The investment decisions in steel mills are taken in an environment of uncertainties, in which the volatility of the steel prices and the variability of the demanded quantities have the capacity of altering, significantly, the economic performance of projects in this sector. In semi-integrated steel mills, this problem can be lessened by the reduction of production or even by the interruption of production for a certain period. This strategic alternative, however, is not available for integrated steel mills, for the blast furnaces have the disadvantage of needing to work continuously, with little flexibility in the adjustment of scale. On the other hand, the integrated steel mills, normally, invest in rolling assets that allow them to produce different types of steel products. Taking into account that these steel products are consumed by several industries and their price variations are correlated, but not identical along time, these investments can generate valuable product switch options.

In this work, the Monte Carlo simulation was used, analyzing the value of a product switch option in a hypothetical integrated steel mill, constituted by a blast furnace and a rolling mill both with the maximum production capacity of 2.8 million tons/year. As models of price behavior, two different types of stochastic processes were considered, the Regression to Mean Model (MRM) and the Geometric Brownian Motion (GBM). The results obtained point out that, independently of the choice processes, this option has a significant value that increases, considerably, the value created for the stockholders of integrated steel projects. In some cases, this important real option can even make the difference in relation to the viability of the project itself. However, the correct determination of the stochastic process most adequate for modeling of the uncertainties involved can be of great influence on the valuation of the real option. In the case analyzed, the difference in value of the calculated option using 
two different stochastic processes actually is important, although its value still remains significant. The choice of stochastic diffusion model is, therefore, essential in the modeling of the real options in projects connected to commodities. As a suggestion for future works in this area, other options can be investigated, such as the option of temporary suspension and the option to scale expansion.

\section{REFERENCES}

BASTIAN-PINTO, C.; BRANDÃO, L. E. T.; HAHN, W. J. Flexibility as a source of value in the production of alternative fuels: the ethanol case. Energy Economics, v. 31, n. 3, p. 335510, maio, 2009.

BJERKSUND, P.; EKERN, S. Managing investment opportunities under price uncertainty: from "last chance" to "wait and see" strategies. Financial Management, v. 3, n. 19, p. 65-83, Autumn 1990.

BLANK, F. B.; BAYDIA, T. K. N.; DIAS, M. A. G. Private infrastructure investment through public private partnership: an application to a toll road highway concession in Brazil. In: ANNUAL INTERNATIONAL CONFERENCE ON REAL OPTIONS, 13., 2009. Anais...UNIVERSITY OF MINHO, PORTUGAL \& UNIVERSITY OF SANTIAGO DE COMPOSTELA, ESPANHA, 17-20 jun. 2009.

BLOOMBERG - Business, Financial \& Economic News Stock Quotes. Disponível em:

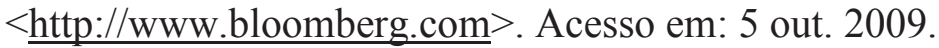

BM\&FBOVESPA. Disponível em: $<$ http://www.bmfbovespa.com.br/home.aspx?idioma=ptbr>. Acesso em: 5 jan. 2011.

BRANDÃO, L. E. T.; SARAIVA, E. C. G. Risco privado em infra-estrutura pública: uma análise quantitativa de risco como ferramenta de modelagem de contratos. Revista de Administração Pública, v. 41, n. 6, p. 1035-1057, nov./dez. 2007.

BRENNAN, M. J.; SCHWARTZ, E. S. Evaluating natural resource investment. Journal of Business, v. 58, n. 2, p. 135-157, 1985.

CAULEY, S. D.; PAVLOV, A. D. Rational delays: the case of real estate. Journal of Real Estate Finance and Economics, v. 24, n. 1-2, p.143-165, 2002.

DAMODARAN, A. Levered and unlevered betas for industry. Disponível em: <www.damodaran.com>. Acesso em: 5 jan. 2011.

DIAS, M. A. G.; ROCHA, K. Petroleum concessions with extendible options using mean reversion with jumps to model oil prices. In: ANNUAL INTERNATIONAL CONFERENCE ON REAL OPTIONS, 3., 1999, Wassenaar/Leiden. Anais... Wassenaar/Leiden, Holanda, 1999.

DIXIT, A. K.; PINDYCK, R, S. Investment under uncertainty. New Jersey: Princeton University Press, 1994. 
DOCKENDORF, J.; PAXSON, D. the value of switching outputs in a fertilizer plant in the US. In: ANNUAL INTERNATIONAL CONFERENCE ON REAL OPTIONS, 13., 2009. Anais...UNIVERSITY OF MINHO, PORTUGAL \& UNIVERSITY OF SANTIAGO DE COMPOSTELA, ESPANHA, 17-20 jun. 2009.

FORTUNATO, G. et al. Valor da opção de abandono em lançamentos imobiliários residenciais. RAC Eletrônica, v. 2, n. 3, p. 531-545, set./dez. 2008.

GOMES, L. L. Avaliação de termelétricas no Brasil: estudando o melhor momento de investimento por modelos de opções reais. 2002. 104 f. Tese (Doutorado em Engenharia) Departamento de Engenharia Industrial, Pontifícia Universidade Católica do Rio de Janeiro, 2002.

HERBELOT, O. Option valuation of flexible investments: the case of environmental investments in the electric power industry. Thesis (Ph. D.) - Dept. of Nuclear Engineering, Massachusetts Institute of Technology, Massachusetts, 1992.

HULL, J. C. Options, futures, and other derivatives securities. 6. ed. Englewood Cliffs, NJ: Prentice Hall, 2006.

INSTITUTO AÇO BRASIL (IBS). Rio de Janeiro, 2009. Disponível em:

$<$ http://www.acobrasil.org.br $>$. Acesso em: 3 out. 2009.

IMF \& WORLD STEEL ASSOCIATION. Disponível em: <www.imf.org>. Acesso em: 5 out. 2009.

IRWIN, T. Public money for private infrastructure. World Bank Working Paper, n. 10, 2003. Disponível em:

$<\underline{\text { http://rru.worldbank.org/Documents/PapersLinks/Public\%20Money\%20for\%20Private } \% 20 \mathrm{I}}$ nfrastructure.pdf $>$.

MOREIRA, A.; ROCHA, K.; DAVID, P. Thermopower generation investment in Brazil: economic conditions. Energy Policy, n. 32, n. 1, p. 91-100, jan. 2004.

MYERS, S. Determinants of corporate borrowing. Journal of Financial Economics, v. 5, n. 2, p. 147-175, nov. 1977.

PINDYCK, R. S. The dynamics of commodity spot and futures markets: a primer. The Energy Journal, v. 22, n. 3, p. 1-29, ago. 2001.

PINDYCK, R. S. The long run evolution of energy prices. The Energy Journal, v. 20, n. 2, p. 1-27, 1999.

QUIGG, L. Empirical testing of real option: pricing models. The Journal of Finance, v. 48, n. 2, p. 621-641, jun. 1993.

SCHWARTZ, E. S. The stochastic behavior of commodity prices: implications for valuation and hedging. The Journal of Finance, v. 52, n. 3, p. 923-973, jul. 1997.

SCHWARTZ, E. S.; SMITH, J. E. Short-term variations and long-term dynamics in commodity prices. Management Science, v. 46, n. 7, p. 893-911, jul. 2000. 
TITMAN, S. Urban land prices under uncertainty. The American Economic Review, v. 75, n. 3, p. 505-514, jun. 1985.

TOURINHO, O. A. F. The valuation of reserves of natural resources: an option pricing approach. Tese (Doutorado em Administração.) - University of California, Berkeley, 1979.

WILLIAMS, J. Real state development as an option. Journal of Real Estate Finance and Economics, v. 4, n. 2, p. 191-208, jun. 1991.

WORLD STEEL ASSOCIATION. Brussels - Belgium, 2009. Disponível em: $<$ http://www.worldsteel.org $>$. Acesso em: 3 out. 2009.

WORLD STEEL DYNAMICS INC. - Global Steel Export Pricing: Forecast to 2018, July 2008. Disponível em: $<$ http://www.worldsteeldynamics.com/subscription/publist2008.html $>$. Acesso em: 20 out. 2009. 